\title{
RESEARCH
}

Open Access

\section{Incidence of tuberous sclerosis and age at first diagnosis: new data and emerging trends from a national, prospective surveillance study}

Daniel Ebrahimi-Fakhari ${ }^{1 *}$ (D), Lilian Lisa Mann ${ }^{1}$, Martin Poryo ${ }^{2}$, Norbert Graf ${ }^{3}$, Rüdiger von Kries ${ }^{4,5}$, Beate Heinrich ${ }^{5}$, Darius Ebrahimi-Fakhari ${ }^{6}$, Marina Flotats-Bastardas ${ }^{1}$, Ludwig Gortner ${ }^{1}$, Michael Zemlin ${ }^{1}$ and Sascha Meyer ${ }^{1}$

\begin{abstract}
Background: Tuberous Sclerosis Complex (TSC) is a rare multisystem disorder. In 2012 diagnostic criteria for TSC were revised. However, data on the incidence of TSC are limited.

Methods: Prospective, national surveillance study in Germany over a 2-year-period (03/2015-02/2017) using current revised criteria for TSC. Patients up to the age of 18 years with a new diagnosis of definite or possible TSC (clinical and/or genetic) were included. The aims of this study were 1) to generate up-to-date data on the incidence of definite or possible TSC, 2) to assess age at first diagnosis, and 3) to compare these data with previous epidemiologic data.

Results: In total, 86 patients met inclusion criteria (definite or possible TSC) with a median age at diagnosis of 6 months (range: 5 months before birth - 197 months of age). Among patients identified with features of TSC, 73.3\% met criteria for definite diagnosis (median age: 7 months) and 26.7\% met criteria for a possible diagnosis (median age: 3 months). $55.8 \%$ of patients were male. When excluding prenatally diagnosed patients, median age at diagnosis was 11 months with a range of 0 to 197 months. The 3 most common clinical features at diagnosis of TSC were central nervous system involvement in 73.3\% patients (of these 95.2\% experienced seizures), cutaneous involvement in 58.1\% patients (with the most common lesion being hypomelanotic macules in 92\%) and cardiac rhabdomyoma in half of the patients. Cardiac rhabdomyoma were detected by prenatal ultrasonography in $22.1 \%$ of patients. The presence of cardiac rhabdomyoma was associated with cardiac arrhythmias in $25.6 \%$ (about 13\% of all diagnosed patients) in our cohort. The overall prevalence of seizure disorders was $69.8 \%$. The annual incidence rate of TSC is estimated at a minimum of 1:17.785 live births. However correcting for underreporting, the estimated incidence rate of definite or possible TSC is approximately 1:6.760-1:13.520 live births in Germany.

Conclusions: This is the first study that assessed prospectively the incidence rate of TSC in children and adolescents using the updated diagnostic criteria of 2012. This prospective surveillance study demonstrates a low age at first diagnosis (median: 6 months), likely due to antenatal detection of cardiac rhabdomyoma. Early diagnosis bears the potential for implementing effective therapies at an earlier stage.
\end{abstract}

Keywords: Epidemiology, Incidence, Tuberous sclerosis, Everolimus, mTOR, Prenatal rhabdomyoma, hamartomas, Neurologic manifestations, Infantile spasms, Seizures

\footnotetext{
* Correspondence: daniel.ebrahimifakhari@uks.eu

${ }^{1}$ Department of Pediatric Neurology, Saarland University Medical Center,

Building 9, Kirrberger Strasse, 66421 Homburg, Saarland, Germany

Full list of author information is available at the end of the article
}

(c) The Author(s). 2018 Open Access This article is distributed under the terms of the Creative Commons Attribution 4.0 International License (http://creativecommons.org/licenses/by/4.0/), which permits unrestricted use, distribution, and reproduction in any medium, provided you give appropriate credit to the original author(s) and the source, provide a link to the Creative Commons license, and indicate if changes were made. The Creative Commons Public Domain Dedication waiver (http://creativecommons.org/publicdomain/zero/1.0/) applies to the data made available in this article, unless otherwise stated. 


\section{Background}

Tuberous Sclerosis Complex (TSC) is a rare genetic neurocutaneous, multisystem disorder with a variable clinical phenotype [1-3]. It is characterized by autosomal-dominant mutations in the TSC1 or TSC2 genes (encoding for the protein Hamartin on chromosome 9q34 and Tuberin on chromosome 16q13 respectively) [4-6], leading to overactivation of the mTOR (mechanistic target of rapamycin) pathway with increased cell proliferation and a range of other consequences [7]. Benign tumor growth represents the hallmark of the disease with the central nervous system (CNS), the kidney and the skin being the most commonly affected organs. TSC features develop in an age dependent manner [8]. In 2012, the Tuberous Sclerosis Consensus Conference updated diagnostic criteria and surveillance management of the disease (Table 1) $[9,10]$.

In recent years large-scale data on the clinical and genetic characteristics have emerged, most importantly from the TOSCA (TuberOus SClerosis registry to increase disease Awareness) study. The TOSCA study is a large natural history study encompassing 2093 patients with TSC [11]. In this registry, the median age of diagnosis of TSC was one year (range 0-69). In 5.9\% patients, the diagnosis was made antenatally. While cardiac rhabdomyoma were found in $34.3 \%$ patients, mean age of diagnosis of cardiac rhabdomyoma was 3.1 years. Whilst knowledge of clinical and genetic features of TSC has increased and treatment modalities have been established, there is still a lack of prospective studies on the incidence of TSC [11-16].

The German Paediatric Surveillance Unit (ESPED) was founded in 1992 to generate incidence data and detailed clinical descriptions of rare, childhood-onset diseases in Germany requiring in-hospital treatment $[17,18]$. Electronic mailing cards are sent monthly to the heads of all pediatric departments in Germany asking whether a patient was newly diagnosed with one of the 12 rare clinical conditions currently under review (active surveillance system, i.e. negative reporting (no cases) as well) [19]. In case of a positive answer, a detailed questionnaire is sent to the reporting hospital by ESPED. Survey periods usually last two years. In addition to epidemiological data, further information from extended laboratory testing or genetic analyses can be integrated into individual research projects. Between 1992 and 2017, ESPED completed 96 prospective studies on rare diseases in children [18]. Thus, ESPED surveys are an important contributor in the field of clinical epidemiology in children with rare diseases [19].

The major aims of this prospective, national surveillance study were:

1) To generate up-to-date data on the incidence of definite or possible TSC in Germany over a 2-yearperiod using current revised criteria for TSC
Table 1 Diagnostic criteria according to the 2012 International Tuberous Sclerosis Complex Consensus Conference [9]

Definite diagnosis: Two major diagnostic criteria or one major with greater than or equal two minor diagnostic criteria or the presence of a TSC1 or TSC2 mutation (of confirmed pathogenicity ${ }^{\mathrm{a}}$ )

Possible diagnosis: Either one major diagnostic criteria or greater than or equal two minor diagnostic criteria

$\begin{array}{ll}\text { Major criteria: } & \text { - Cortical dysplasias (incl. tubers and cerebral white } \\ & \text { matter radial migration lines) } \\ & \text { - Subependymal nodules (SEN) } \\ & \text { - Subependymal giant cell astrocytoma (SEGA) } \\ & \text { - Cardiac rhabdomyoma } \\ & \text { - Hypomelanotic macules ( } \geq 3 \text {, at least } 5 \mathrm{~mm} \text { diameter) } \\ & \text { - Angiofibromas }(n \geq 3) \text { or fibrous cephalic plaque } \\ & \text { - Ungual fibromas }(\geq 2) \\ & \text { - Shagreen patch } \\ & \text { - Angiomyolipomas }(\geq 2) \text { b, c } \\ & \text { - Lymphangioleiomyomatosis (LAM) }{ }^{\text {b }} \\ & \text { - Multiple retinal hamartomas } \\ & \text { - 'Confetti' skin lesions } \\ & \text { - Dental enamel pits ( }>3) \\ & \text { - Intraoral fibromas }(\geq 2) \\ \text { Minor criteria: } & \text { Multiple renal cysts } \\ & \text { - Retinal achromatic patch } \\ & \text { - Nonrenal hamartomas } \\ & \text { Identification of either a TSC1 or TSC2 pathogenic } \\ \text { Genetics: } & \text { mutation in DNA from normal tissue }\end{array}$

(From: Northrup H, Krueger DA, on behalf of the International Tuberous Sclerosis Complex Consensus Group. Tuberous Sclerosis Complex Diagnostic Criteria Update: Recommendations of the 2012 International Tuberous

Sclerosis Complex Consensus Conference. Pediatr Neurol 2013; 49: 243-254. () The authors. License Number 4341381420907)

${ }^{a}$ Pathogenic mutation: a mutation that clearly inactivates the function of the TSC1 or TSC2 proteins (e.g., out-of-frame indel or nonsense mutation), prevents protein synthesis (e.g., large genomic deletion), or is a missense mutation whose effect on protein function has been established by functional assessment (www.lovd.nl/TSC1, www.lovd/nl/TSC2 and Hoogeveen-Westerveld et al., 2012 and 2013). Other TSC1 or TSC2 variants whose effect on function is less certain do not meet these criteria, and are not sufficient to make a definite diagnosis of TSC. Note that 10 to $25 \%$ of TSC patients have no mutation identified by conventional genetic testing, and a normal result does not exclude TSC, or have any effect on the use of clinical diagnostic criteria to diagnose TSC

${ }^{\mathrm{b}} \mathrm{A}$ combination of the two major clinical features (lymphangioleiomyomatosis and angiomyolipomas) without other features does not meet criteria for a definite diagnosis

c Angiomyolipomas might also occur in the liver or other organ systems

2) To assess age at first diagnosis, and

3) To compare our results with previous epidemiologic data

\section{Methods}

This study was a prospective, national surveillance study conducted from March 1, 2015 to February 28, 2017 in Germany. The study was approved by the Institutional Ethics Review Board of Saarland, Germany (file no. 219/14). Patients up to the age of 18 years with a new diagnosis of definite or possible TSC [9] (clinical and/or genetic) were prospectively included.

Electronic and postal questionnaires (see Additional file 1) were sent monthly to all departments of pediatrics $(n=349)$, all social pediatric centers $(n=120)$ and TSC centers $(n=18)$ in Germany, using the German Paediatric 
Surveillance Unit for Rare Diseases (ESPED) system [17-19]. Statistical analysis was performed using IBM SPSS Statistics version 24 (IBM, Armonk, NY, USA). Descriptive data are presented as median and range. The incidence rate of TSC is estimated from the number of live births in Germany (737.575 in 2015 and 792.000 in 2016) during the study period. For estimating the potential size of underreporting, we used estimates from previous ESPED studies with correction factors for completeness between $0.38-0.76[17,18]$.

For classification of patients with a definite or possible diagnosis of TSC, we used the current Tuberous Sclerosis Consensus Conference updated diagnostic guidelines [9].

\section{Results}

Initially 150 cases were reported to ESPED, from which 135 patient questionnaires were received (response rate 90\%). 40 questionnaires did not report TSC patients and 9 contained redundant datasets (double reporting) and were excluded. In total, 86 patients met inclusion criteria. Median age at diagnosis (definite or possible TSC) was 6 months (range: 5 months before birth -197 months of age). Among patients identified with features of TSC, 73.3\% (63/86) met criteria for definite diagnosis (median age: 7 months; range: 5 months before birth -139 months of age) and $26.7 \%(23 / 86)$ met criteria for a possible diagnosis (median age: 3 months; range: 1 month before birth - 197 months of age). 55.8\% (48/86) of patients were male. Age at diagnosis is shown in Fig. 1. When excluding prenatally diagnosed patients (19/86), median age at diagnosis (definite or possible TSC) was 11 months with a range of 0 to 197 months.

\section{Incidence}

Based on our findings, the annual incidence rate of TSC (definite or possible TSC) is estimated at a minimum of 1:17.785 live births. However correcting for underreporting using data from previous ESPED analyses, the estimated incidence rate of definite or possible TSC is approximately 1:6.760-1:13.520 live births in Germany.

\section{Clinical features \\ Antenatal characteristics}

Cardiac rhabdomyoma were detected by antenatal ultrasound in $22.1 \%$ of patients (19/86), leading to antenatal diagnosis of 'possible TSC'. One patient had concomitant cerebral abnormalities (no other characteristics were reported).

\section{Postnatal characteristics}

The most common clinical feature at diagnosis of TSC was central nervous system (CNS) involvement in $73.3 \%$ patients (63/86), of these $95.2 \%(60 / 63)$ experienced seizures. Hence, the overall prevalence of seizure disorders in our cohort was $69.8 \%(60 / 86)$. Cutaneous involvement was seen in $58.1 \%$ patients $(50 / 86)$; with the most common lesion being hypomelanotic macules in $92 \%(46 / 50)$. Cardiac rhabdomyoma manifested in half of the patients (43/86), $25.6 \%$ of these (11/43) with cardiac arrhythmia.

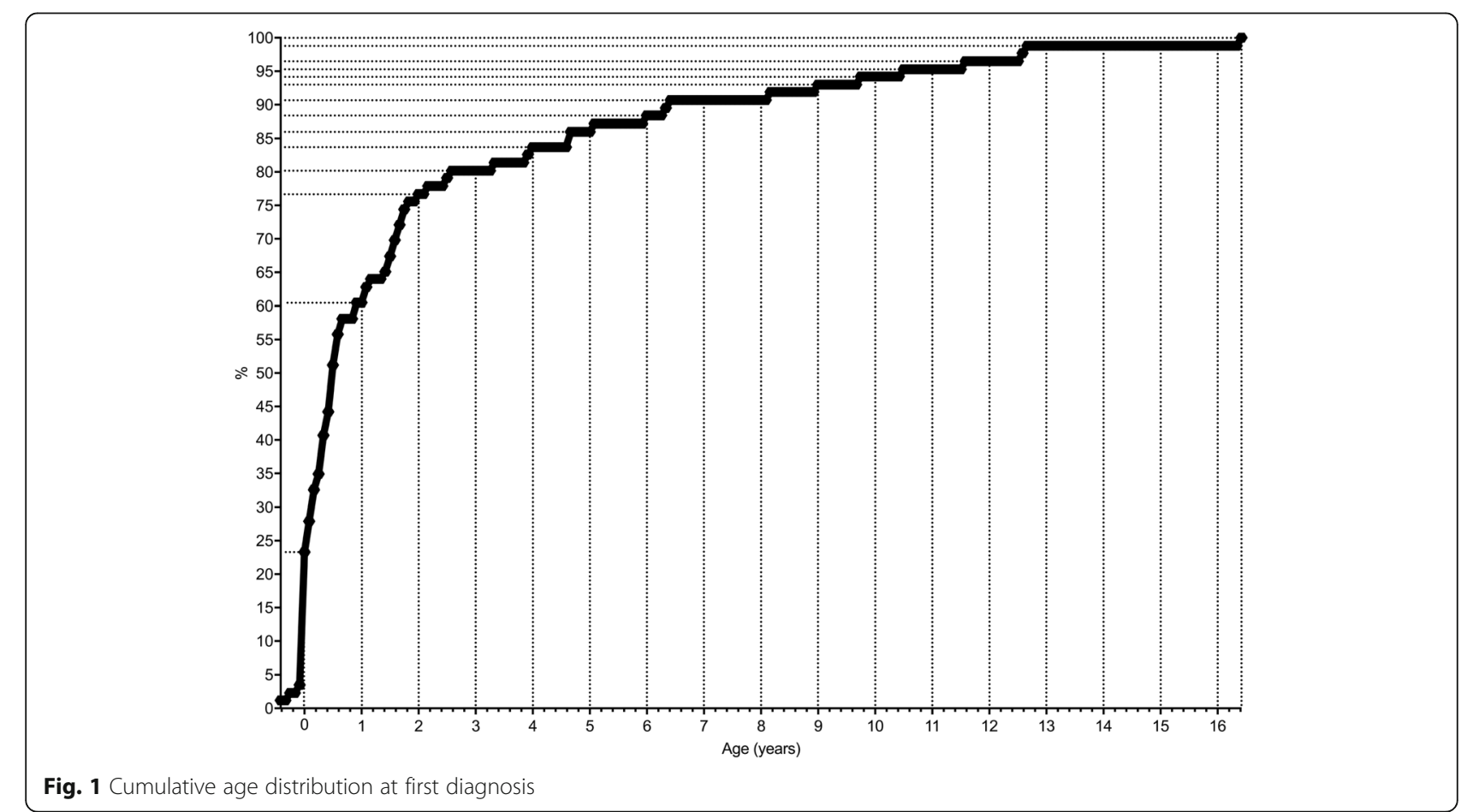


The spectrum of TSC manifestations other than cardiac, cutaneous and CNS involvement was heterogeneous (Fig. 2). Results from comprehensive diagnostic workup, following surveillance and management recommendations for newly diagnosed or suspected TSC [10] are detailed in Fig. 3.

\section{Diagnostic tests}

Tests used to establish the diagnosis are detailed in Fig. 4. The most common diagnostic study performed was echocardiography in $90.7 \%$ (78/86), followed by ultrasound (cerebral or abdominal) in $89.5 \%$ (77/86). An electroencephalogram (EEG) was performed in $84.9 \%(73 / 86)$ of cases. Cranial magnetic resonance imaging (cMRI) was obtained in $74.4 \%(64 / 86)$ as well as cranial CT imaging in 3 patients (3.4\%). A formal skin examination by a dermatologist was only performed in $33.7 \%$ (29/86), while cutaneous involvement was noted in $58.1 \%$ of all patients.

\section{Genetics}

Results from genetic testing were available in $53.5 \%$ patients (46/86): (TSC1: 21.7\% (10/46); TSC2: 58.7\% (27/46); no mutation identified (NMI) 19.6\% (9/46)). Of note, two patients with TSC2 mutation also had a PKD1 mutation (contiguous gene syndrome). A family history of TSC was found in 13 of 86 patients (15.1\%).

\section{Discussion}

We here present a prospective epidemiological study that aimed at determining the incidence of TSC, using the current revised diagnostic criteria from 2012 Tuberous
Sclerosis Consensus Conference [9]. Although our study provides an estimate of the incidence of definite or possible TSC in Germany based on active surveillance data, we assume that the true incidence is probably still under-estimated for the following reasons:

The true number of TSC patients in our study is unknown. Reporting bias could not be estimated by capture-recapture analysis since no independent second data source was available. We used estimates from previous ESPED studies to estimate a range for potential underreporting (between 0.38-0.76). Interestingly, our incidence data were similar to previous reports, where incidence rates in adults were calculated by employing prevalence data analysis [12]. Our data are also corroborated by a retrospective nationwide cohort study (1997-2010) estimating the incidence of TSC at 0.153 per 100.000 person years in Taiwan [20]. Ascertainment bias remains a possible confounder because of the broad spectrum of disease manifestations and severity, rendering a clinical diagnosis of TSC challenging in mildly affected individuals (e.g. with mosaicism in NMI patients) [21, 22]. In addition, there are TSC patients with NMI (10-15\%), in which mosaicism and intronic mutations have only been detected by using next generation sequencing (in $85 \%$ of NMI patients) [22]. We acknowledge that these genetic approaches are not yet current standard of care, especially if a definite diagnosis is made using clinical diagnostic criteria. However, with increasing availability of next generation sequencing, early genetic diagnoses will become more common. Genetic testing was not a pre-requisite for study participation; hence

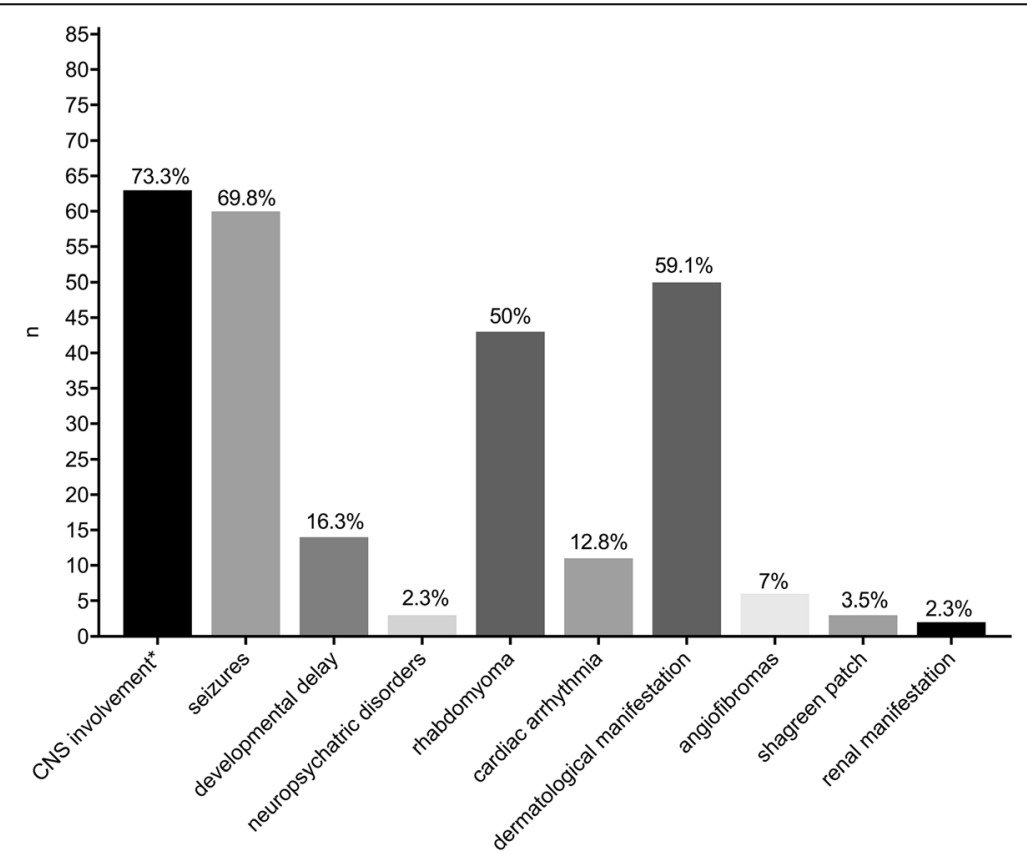

Fig. 2 Clinical features leading to first diagnosis. * Including seizures, developmental delay, neuropsychiatric disorders (e.g. autistic characteristics); multiple entries possible. Abbreviations: CNS (central nervous system); (n: number of patients) 


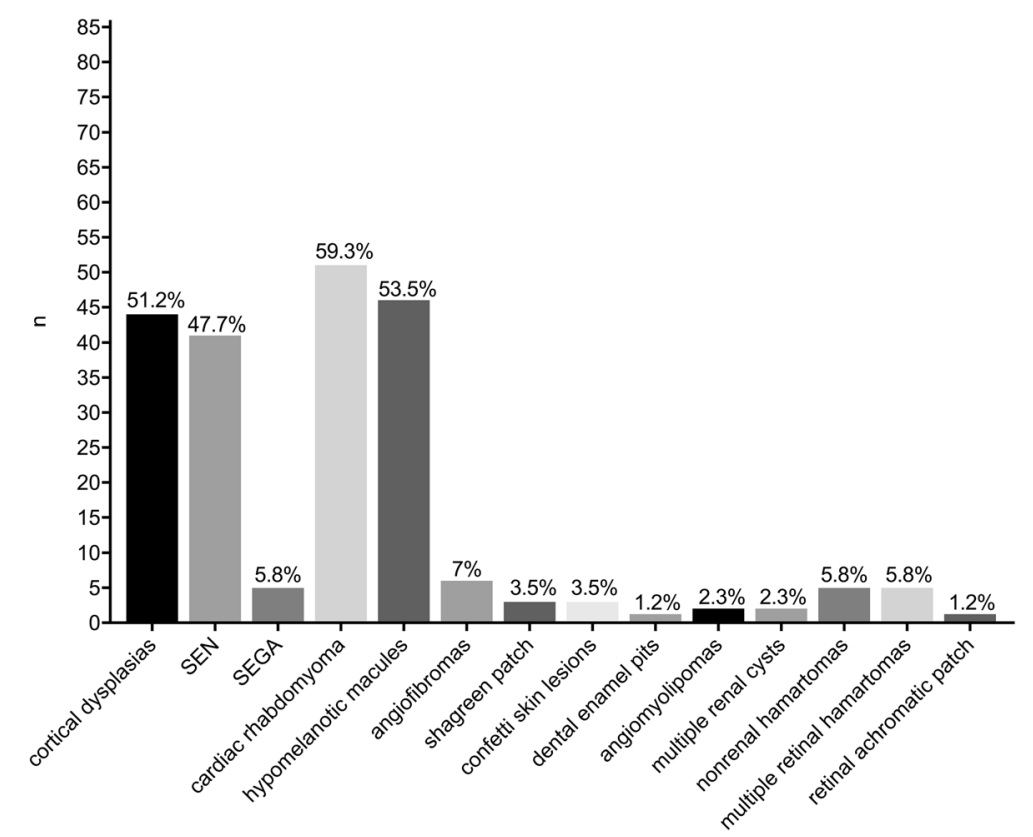

Fig. 3 Clinical features after comprehensive diagnostic work-up. The majority of patients presented with CNS involvement (cortical dysplasias 51.5\% (44/86); subependymal nodules (SEN) 47.7\% (41/86) and subependymal giant cell astrocytoma (SEGA) 5,8\% (5/86). Followed by cardiac rhabydomyoma in 59.3\% (51/86) and hypomelanotic macules in 53.5\% (46/86). The other clinical symptoms were heterogeneous. (n: number of patients)

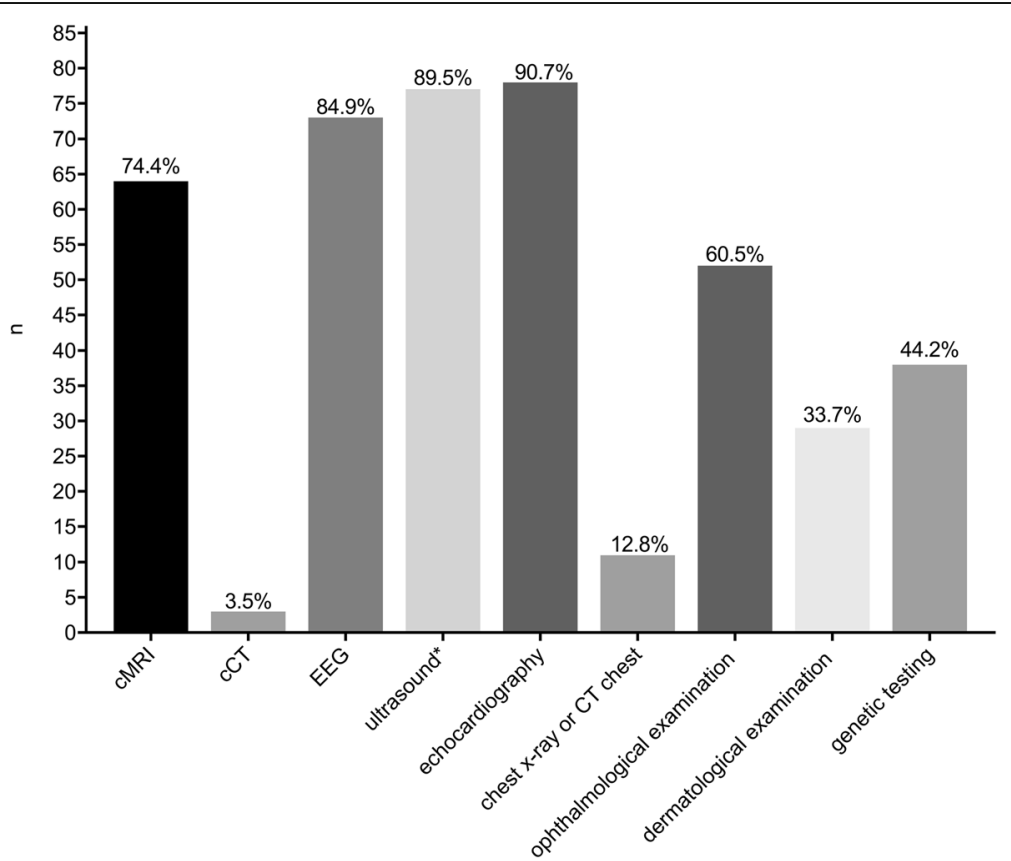

Fig. 4 Tests used to establish the diagnosis. The most common diagnostic study performed was echocardiography in 90.7\% (78/86), followed by ultrasound (cerebral or abdominal) in 89.5\% (77/86). An electroencephalogram (EEG) was performed in 84.9\% (73/86). Cranial magnetic resonance imaging (CMRI) was obtained in 74.4\% (64/86) as well as cranial CT imaging in 3 patients (3.4\%). Formal skin examination was only performed in $33.7 \%$ (29/86), while cutaneous involvement was noted in $58.1 \%$ of all patients. (n: number of patients) 
results from genetic testing were only available in 53.5\% patients. This is comparable to the data from the TOSCA registry, where genetic testing was performed in 43.1\% patients [11]. Given the age-related expression of TSC, one shortcoming of our study was that we were not able to assess the number of children with a possible diagnosis who would eventually develop a definite diagnosis of TSC, thus potentially overestimating the true incidence of TSC. When comparing our incidence results with published work on TSC incidence, it is important to note that in the report by Osborne et al. from 1993 a different set of diagnostic criteria was used. In this study cases were classified as "definitive" and "presumptive" to generate incidence data [13]. These two different approaches may have contributed to differences in incidence rates between the two studies [13].

TSC is a very heterogeneous disorder both with regard to age-related expression and variability of clinical manifestations [1]. Of note, age at first diagnosis in our study was substantially lower than in previous epidemiological reports $[11,16]$, with the most prominent features being cardiac rhabdomyoma, CNS and skin involvement, while other characteristics features of TSC (e.g. facial angiofibroma, angiomyolipoma, lymphangioleiomyomatosis) were seen less frequently. In the TOSCA study, TSC was diagnosed at a median age of one year (range 0-69) [11]. The shift towards a younger age at diagnosis seen in our cohort can be attributed to a substantial number of TSC patients with prenatally detected cardiac rhabdomyoma and to the study design that only assessed patients up to 18 years in our survey. The tendency towards a lower age at first diagnosis is consistent with a recently published study by Davis et al. in which cardiac rhabdomyoma were the most common initial presenting feature of TSC [23]. Compared to the TOSCA study, in which cardiac rhabdomyoma were found in $34.3 \%$ patients, our cohort showed a higher prevalence of cardiac rhabdomayoma in $50 \%$ of the patients. Of note and in contrast with findings from the TOSCA registry, arrhythmias/dysrhythmias were also more frequent in our study (5.6\% vs. $25.6 \%)$. Cardiac rhabdomyoma are highly suggestive of TSC disease [24], mandating further diagnostic work-up in order to establish an early diagnosis. If TSC is diagnosed antenatally, careful monitoring should be implemented using the current international surveillance and management guidelines [10]. Of note, the incidence of cardiac arrhythmias of $25.6 \%$ in those with rhabdomyoma (about 13\% of all diagnosed patients) in our cohort is high. Moreover, it can be speculated that implementation of a standardized antenatal screening program with fetal ultrasonography and increased awareness for TSC disease has led to an earlier diagnosis - most likely by earlier detection of children with subtle clinical symptoms [11]. Routine antenatal ultrasound examination performed at a gestational age of 19-22 weeks in Germany may possibly miss a certain percentage of 'late onset' cardiac rhabdomyoma. In a study by Bader et al. the mean gestational age at diagnosis of cardiac rhabdomyoma was $28.4 \pm 6.0$ weeks (median 28; range 19-37) [24]. However, no serial antenatal ultrasound examinations were performed in this study. Hitherto, there are few off-label studies that reveal effective usage of mTOR inhibition for cardiac rhabdomyoma [25]. Further studies on the natural history of (antenatally detected) cardiac rhabdomyoma in TSC and on possible preventative treatment interventions in severe cases (e.g. critical arrhythmias) are needed, in particular in the light of the unknown prognostic significance of rhabdomyoma associated arrhythmias in TSC.

CNS involvement was the most common clinical symptom at diagnosis in our study. These findings are congruent with the results from Davis et al. demonstrating a prevalence of tubers or cortical dysplasia of $94 \%$ in their cohort [23] as well as with the results from the TOSCA study (cortical tubers in $82.2 \%$ ) [11]. The overall prevalence of seizure disorders in our cohort was $69.8 \%$.

With new treatment options (e.g. mTOR inhibitors) for a variety of TSC manifestations (subependymal giant cell astrocytoma (SEGA) [26] and for adjunctive treatment of refractory partial-onset seizures, with or without generalization [27], and renal angiomyolipoma [28]) an early diagnosis and treatment will have a positive impact on the clinical course of children and adolescents with TSC. Moreover, the early use of effective treatment modalities including mTOR inhibitors has not only the potential to ameliorate the clinical course, but also to modify the clinical phenotype (e.g. use of everolimus in EXIST-I and EXIST-II study resulted also in fewer skin involvement). With ongoing changes in diagnostic and therapeutic possibilities, it is imperative to systematically define the spectrum of disease onset. Cutaneous lesions other than hypomelanotic macules (angiofibroma, shagreen patches) is a recognized manifestation, particularly in adult cases [29], and was therefore less frequent in our cohort.

\section{Conclusions}

This is to our knowledge the first population-based estimation of definite or possible TSC incidence in children using current diagnostic criteria, thus providing the medical community with a robust estimate of the incidence of TSC in children. In contrast to our dataset, other studies have reported prevalence rates [12-15] and/or used different diagnostic criteria such as the Roach criteria from 1998 [30] or earlier criteria [13]. Our findings reveal a substantially lower age at first diagnosis of TSC. With the advent and implementation of prenatal imaging the diagnosis of TSC is often made early. In summary, our study demonstrates the presence of cardiac rhabdomyoma in a significant proportion of newly 
prenatally diagnosed TSC patients. The presence of cardiac rhabdomyoma was associated with cardiac arrhythmias in a substantial number of children in our cohort. Early age at diagnosis will open new avenues to new therapeutic interventions; most importantly early and close EEG monitoring and if abnormal, initiation of early anti-epileptic drug treatment [31, 32], but may also result in earlier use of mTOR inhibitors, thus further modifying the clinical trajectory and phenotype in affected children.

\section{Additional file}

Additional file 1: TSC Questionnaire ESPED Germany. (PDF 75 kb)

\section{Abbreviations}

CNS: Central nervous system; ESPED: German Paediatric surveillance unit for rare diseases; mTOR: mechanistic target of rapamycin; NMI: No mutation identified; TOSCA: TuberOus SClerosis registry to increase disease awareness; TSC: Tuberous sclerosis

\section{Acknowledgements}

We would like to thank the German Tuberous Sclerosis Alliance (Tuberöse Sklerose Deutschland e.V.) and the German Tuberous Sclerosis Foundation (Deutsche Tuberöse Sklerose Stiftung), and the German Paediatric Surveillance Unit (ESPED). We are also grateful to Novartis for research funding. We are indebted to all reporting colleagues for their help with this study. Finally, we thank all participating families.

\section{Funding}

This work was supported by the German Tuberous Sclerosis Foundation (Deutsche Tuberöse Sklerose Stiftung) and Novartis. The authors confirm complete independence from the sponsors. The sponsors did not have any influence on neither the content of the article nor on the conceptualization/ design, methodology, investigation, supervision/oversight, data curation, and formal analysis of this study. The authors exclusively wrote this article. The study participants did not receive any compensation for their participation in the study.

\section{Availability of data and materials}

The datasets used and/or analyzed during the current study are available from the corresponding author on reasonable request.

\section{Authors' contributions \\ All authors made substantial contributions. DEF1 and SM wrote the manuscript to which all co-authors contributed as well. DEF1 contributed to conceptualization/design, methodology, investigation, data curation and formal analysis. LLM contributed to data curation and formal analysis. MP, DEF2 and MFB contributed to formal analysis, and critical revision of the manuscript. NG and MZ contributed to supervision/oversight and formal analysis. RVK contributed to conceptualization/design, methodology, investigation, supervision/oversight and formal analysis. BH contributed to conceptualization/design, supervision/oversight and data curation. LG contributed to conceptualization/design and methodology. SM was chief investigator, contributed to conceptualization/design, methodology, investigation, supervision/oversight, funding acquisition, data curation, formal analysis and resources. All authors read and approved the final manuscript.}

Ethics approval and consent to participate

The study was approved by the Institutional Review Board of Saarland, Germany (file no. 219/14).

\section{Consent for publication}

Not applicable.

\section{Competing interests}

The authors declare that they have no competing interests.

\section{Publisher's Note}

Springer Nature remains neutral with regard to jurisdictional claims in published maps and institutional affiliations.

\section{Author details}

${ }^{1}$ Department of Pediatric Neurology, Saarland University Medical Center, Building 9, Kirrberger Strasse, 66421 Homburg, Saarland, Germany. ${ }^{2}$ Department of Pediatric Cardiology, Saarland University Medical Center, Homburg, Germany. ${ }^{3}$ Department of Pediatric Oncology and Hematology, Saarland University Medical Center, Homburg, Germany. ${ }^{4}$ Division of Epidemiology, Institute of Social Pediatrics and Adolescent Medicine, Ludwig Maximilian's University, Munich, Germany. ${ }^{5}$ German Paediatric Surveillance Unit (ESPED), Coordination Center for Clinical Studies, Heinrich Heine University, Düsseldorf, Germany. ${ }^{6}$ Department of Neurology, Boston Children's Hospital, Harvard Medical School, Boston, MA, USA.

Received: 12 January 2018 Accepted: 6 July 2018

Published online: 17 July 2018

\section{References}

1. Henske EP, Jozwiak S, Kingswood JC, Sampson JR, Thiele EA. Tuberous sclerosis complex. Nat Rev Dis Primers. 2016:2:16035.

2. Gomez MR. History of the tuberous sclerosis complex. Brain and Development. 1995;17(Suppl):55-7.

3. Cheadle JP, Reeve MP, Sampson JR, Kwiatkowski DJ. Molecular genetic advances in tuberous sclerosis. Hum Genet. 2000;107:97-114.

4. Curatolo P, Bombardieri R, Jozwiak S. Tuberous sclerosis. Lancet. 2008; 372:657-68.

5. van Slegtenhorst $M$, de Hoogt $R$, Hermans $C$, Nellist $M$, Janssen $B$, Verhoef S, Lindhout D, van den Ouweland A, Halley D, Young J, et al. Identification of the tuberous sclerosis gene TSC1 on chromosome 9q34. Science. 1997;277:805-8.

6. European Chromosome 16 Tuberous Sclerosis C. Identification and characterization of the tuberous sclerosis gene on chromosome 16. Cell. 1993:75:1305-15.

7. Lam HC, Nijmeh J, Henske EP. New developments in the genetics and pathogenesis of tumours in tuberous sclerosis complex. J Pathol. 2017; 241:219-25.

8. Jozwiak S, Schwartz RA, Janniger CK, Bielicka-Cymerman J. Usefulness of diagnostic criteria of tuberous sclerosis complex in pediatric patients. J Child Neurol. 2000;15:652-9.

9. Northrup H, Krueger DA, International Tuberous Sclerosis Complex Consensus G. Tuberous sclerosis complex diagnostic criteria update: recommendations of the 2012 international tuberous sclerosis complex consensus conference. Pediatr Neurol. 2013;49:243-54.

10. Krueger DA, Northrup H, International Tuberous Sclerosis Complex Consensus G. Tuberous sclerosis complex surveillance and management: recommendations of the 2012 international tuberous sclerosis complex consensus conference. Pediatr Neurol. 2013;49:255-65.

11. Kingswood JC, d'Augeres GB, Belousova E, Ferreira JC, Carter T, Castellana R, Cottin V, Curatolo P, Dahlin M, de Vries PJ, et al. TuberOus SClerosis registry to increase disease awareness (TOSCA) - baseline data on 2093 patients. Orphanet J Rare Dis. 2017;12:2

12. O'Callaghan FJ, Shiell AW, Osborne JP, Martyn CN. Prevalence of tuberous sclerosis estimated by capture-recapture analysis. Lancet. 1998:351:1490.

13. Osborne JP, Fryer A, Webb D. Epidemiology of tuberous sclerosis. Ann N Y Acad Sci. 1991;615:125-7.

14. Hunt A, Lindenbaum RH. Tuberous sclerosis: a new estimate of prevalence within the Oxford region. J Med Genet. 1984:21:272-7.

15. Wiederholt WC, Gomez MR, Kurland LT. Incidence and prevalence of tuberous sclerosis in Rochester, Minnesota, 1950 through 1982. Neurology. 1985;35:600-3

16. Kingswood C, Bolton P, Crawford P, Harland C, Johnson SR, Sampson JR, Shepherd C, Spink J, Demuth D, Lucchese L, et al. The clinical profile of tuberous sclerosis complex (TSC) in the United Kingdom: a retrospective cohort study in the clinical practice research datalink (CPRD). Eur J Paediatr Neurol. 2016;20:296-308

17. von Kries R, Heinrich B, Hermann M. Pädiatrische Epidemiologie in Deutschland: Forschungsinstrument ESPED (Erhebungseinheit für seltene pädiatrische Erkrankungen in Deutschland). Monatsschrift Kinderheilkunde. 2001;149:1191-7. 
18. Ebrahimi-Fakhari D, Zemlin M, Sauer H, Poryo M, Graf N, Meyer S. 25 years of ESPED as a surveillance tool for rare diseases in children in Germany: a critical analysis. Klin Padiatr. 2018; PubMed ID: 29614515. https://doi.org/10. 1055/a-0586-4365. [Epub ahead of print]

19. Gobel U, Heinrich B, Krauth KA, Steingruber HJ, von Kries R. Process and outcome quality of the German Paediatric surveillance unit (ESPED). Klin Padiatr. 2010;222:92-7.

20. Hong $\mathrm{CH}$, Tu HP, Lin JR, Lee CH. An estimation of the incidence of tuberous sclerosis complex in a nationwide retrospective cohort study (1997-2010). Br J Dermatol. 2016;174:1282-9.

21. Sancak O, Nellist M, Goedbloed M, Elfferich P, Wouters C, Maat-Kievit A, Zonnenberg B, Verhoef S, Halley D, van den Ouweland A. Mutational analysis of the TSC1 and TSC2 genes in a diagnostic setting: genotypephenotype correlations and comparison of diagnostic DNA techniques in tuberous sclerosis complex. Eur J Hum Genet. 2005:13:731-41.

22. Tyburczy ME, Dies KA, Glass J, Camposano S, Chekaluk Y, Thorner AR, Lin L, Krueger D, Franz DN, Thiele EA, et al. Mosaic and Intronic mutations in TSC1/TSC2 explain the majority of TSC patients with no mutation identified by conventional testing. PLoS Genet. 2015;11:e1005637.

23. Davis PE, Filip-Dhima R, Sideridis G, Peters JM, Au KS, Northrup H, Bebin EM, Wu JY, Krueger D, Sahin M, Tuberous Sclerosis Complex Autism Center of Excellence Research N. Presentation and diagnosis of tuberous sclerosis complex in infants. Pediatrics. 2017;140(6). https://doi.org/10.1542/peds. 2016-4040. Epub 2017 Nov 3. PubMed ID: 29101226

24. Bader RS, Chitayat D, Kelly E, Ryan G, Smallhorn JF, Toi A, Hornberger LK. Fetal rhabdomyoma: prenatal diagnosis, clinical outcome, and incidence of associated tuberous sclerosis complex. J Pediatr. 2003;143:620-4.

25. Dahdah N. Everolimus for the treatment of tuberous sclerosis complex-related cardiac Rhabdomyomas in pediatric patients. J Pediatr. 2017;190:21-6. e27

26. Franz DN, Belousova E, Sparagana S, Bebin EM, Frost MD, Kuperman R, Witt $\mathrm{O}$, Kohrman MH, Flamini JR, Wu JY, et al. Long-term use of Everolimus in patients with tuberous sclerosis complex: final results from the EXIST-1 study. PLoS One. 2016;11:e0158476.

27. French JA, Lawson JA, Yapici Z, Ikeda H, Polster T, Nabbout R, Curatolo P, de Vries PJ, Dlugos DJ, Berkowitz N, et al. Adjunctive everolimus therapy for treatment-resistant focal-onset seizures associated with tuberous sclerosis (EXIST-3): a phase 3, randomised, double-blind, placebo-controlled study. Lancet. 2016;388:2153-63.

28. Bissler JJ, Kingswood JC, Radzikowska E, Zonnenberg BA, Frost M, Belousova E, Sauter M, Nonomura N, Brakemeier S, de Vries PJ, et al. Everolimus for angiomyolipoma associated with tuberous sclerosis complex or sporadic lymphangioleiomyomatosis (EXIST-2): a multicentre, randomised, doubleblind, placebo-controlled trial. Lancet. 2013;381:817-24.

29. Ebrahimi-Fakhari D, Meyer S, Vogt T, Pfohler C, Muller CSL. Dermatological manifestations of tuberous sclerosis complex (TSC). J Dtsch Dermatol Ges. 2017;15:695-700

30. Roach ES, Gomez MR, Northrup H. Tuberous sclerosis complex consensus conference: revised clinical diagnostic criteria. J Child Neurol. 1998;13:624-8.

31. Auvin S, Walker L, Gallentine W, Jozwiak S, Tombini M, Sills GJ. Prospective clinical trials to investigate clinical and molecular biomarkers. Epilepsia. 2017;58(Suppl 3):20-6.

32. Benvenuto A, Moavero R, Graziola F, Siracusano M, Emberti Gialloreti L, Aronica E, Jansen A, Jansen FE, Jozwiak S, Kotulska-Jozwiak K, et al. Prospective serial neuropsychological study in infants with tuberous sclerosis complex (TSC): first analysis from the EPISTOP project. Eur J Paediatr Neurol. 2017;21:e23.

\section{Ready to submit your research? Choose BMC and benefit from:}

- fast, convenient online submission

- thorough peer review by experienced researchers in your field

- rapid publication on acceptance

- support for research data, including large and complex data types

- gold Open Access which fosters wider collaboration and increased citations

- maximum visibility for your research: over $100 \mathrm{M}$ website views per year

At BMC, research is always in progress.

Learn more biomedcentral.com/submissions 